American Journal of Animal and Veterinary Sciences 4 (1): 14-20, 2009

ISSN 1557-4555

(C) 2009 Science Publications

\title{
Influence of the Prostatic Fluid from the First and Third Fractions of the Ejaculates on the Cryosurvival of Poodle Dog Sperm
}

\author{
${ }^{1}$ Hideaki Yamashiro, ${ }^{2}$ Kaori Narita, ${ }^{1}$ Satoshi Sugimura, ${ }^{1}$ Atsushi Sugawara, ${ }^{1}$ Yumi Hoshino, \\ ${ }^{1}$ Masahiro Sakurai, ${ }^{3}$ Masaki Yokoo, ${ }^{2}$ Tsutomu Konno, ${ }^{2}$ Muneyoshi Yoshida and ${ }^{1}$ Eimei Sato \\ ${ }^{1}$ Laboratory of Animal Reproduction, Graduate School of Agricultural Science, \\ Tohoku University, 1-1 Tsutsumidori-amamiyamachi, Aoba-ku, Sendai 981-8555, Japan \\ ${ }^{2}$ Japan Animal Specialty College, 2-2-2 Ichibancho, Aoba-ku, Sendai 980-0811, Japan \\ ${ }^{3}$ Innovation of New Biomedical Engineering Center, Tohoku University, \\ 1-1 Seiryomachi, Aoba-ku, Sendai 980-8574, Japan
}

\begin{abstract}
Problem statement: Two experiments were conducted to determine the effect of the prostatic fluid from the first and third fractions of the ejaculates on the freezability of poodle dog sperm. Approach: The ejaculates from 2 trained poodle dogs were collected. Effect of prostatic fluid from the first and third fractions of ejaculates on cryosurvival of dog sperm was examined. SDS-PAGE analyses were performed to verify whether there were any modifications in the protein patterns of the first and third fractions. Results: When second fractions of Dog A sperm were combined with the prostatic fluid from the first and third fractions of the ejaculates, sperm motility index was decreased compared to second fractions were collected alone. The post-thaw motility of Dog A sperm was significantly reduced when prostatic fluid from the first and third fractions of the ejaculates was added. The motility of frozen-thawed Dog B sperm did not appear to be altered when it was diluted with either of the prostatic fluids. The major bands present in both prostatic fluids corresponded to proteins with molecular masses of 30 and $75 \mathrm{kDa}$. The amount of proteins in the prostatic fluid from the third fraction was twice-three times as much protein present compared to the first fraction. Conclusion: Collection of the sperm-rich fraction along with either the prostatic fluid from the 1st and 3rd fractions of the ejaculates during sperm processing has varying detrimental effects on the motility characteristics of frozen-thawed sperm.
\end{abstract}

Key words: Freezability, poodle dog sperm, prostatic fluid, raffinose, $30 \mathrm{kDa}$ protein

\section{INTRODUCTION}

Seminal plasma, a physiological secretion from multiple glands of the male reproductive tract, has a variety of biochemical components including the prostasome $^{[1-3]}$ and phospholipid-binding proteins ${ }^{[4,5]}$. It is relatively specific in regulating sperm function and sperm metabolism, survival and transport through the female genital tract as well as in determining the acrosome reaction, egg fertilization and sperm freezability ${ }^{[6-8]}$. The prostate is the only accessory sex gland in the dog. The canine ejaculate consists of three fractions. The first (pre-sperm) fraction has a small volume, contains few to no sperm and originates primarily from prostate gland secretions. The second (sperm-rich) fraction is mainly of epididymal origin and contains little prostatic fluid. The third (post-sperm) fraction contributes the largest volume to the seminal plasma during ejaculation and is predominately made up of prostatic fluid ${ }^{[9,10]}$.

Many studies have reported that seminal plasma contains factors that may influence sperm characteristics. Rota et al. ${ }^{[11]}$ noted that the supplementation of seminal plasma into the extender had a detrimental effect on the canine sperm viability at a low temperature. Sirivaidyapong et al. ${ }^{[12]}$ showed that when the sperm-rich fraction was centrifuged, resuspended in prostatic fluid and further diluted with an extender, the addition of prostatic fluid appeared to negatively alter the motility after thawing of the cryopreserved dog sperm. Epididymal sperm from bull, rabbit and ram was incubated in homologous seminal

Corresponding Author: Hideaki Yamashiro, Laboratory of Animal Reproduction, Graduate School of Agricultural Science, Tohoku University, Sendai 981-8555, Japan Tel: +81-22-717-8687 Fax: +81-22-717-8687 
plasma in an extender and the effect on sperm viability was examined ${ }^{[13]}$. The researchers concluded that seminal plasma is deleterious to epididymal sperm survival in several species. Conversely, Hori et al. ${ }^{[14]}$ attempted to freeze-thaw dog epididymal sperm in order to study the effect of the absence or presence of prostatic fluid during freezing on the conception rate of artificial insemination. They reported that sensitization of epididymal sperm with the prostatic fluid before freezing had a beneficial effect on the freezability and fertility of frozen-thawed epididymal sperm. Furthermore, seminal plasma has been reported to increase the resistance of bull, ram and boar sperm to cold shock $^{[15-18]}$ and to exert a protective effect on the viability of human sperm cryopreservation ${ }^{[19]}$.

Manjunath and Sairam ${ }^{[4]}$ characterized the phospholipid-binding proteins designated as Bovine Seminal Plasma (BSP) proteins, i.e., BSP-A1, BSP-A2, BSP-A3 and BSP-30 kDa. These proteins are secreted from the seminal vesicles and are collectively called BSP proteins; they constitute the major protein fraction in the BSP. These BSP proteins bind to choline phospholipids present on the sperm surface at ejaculation and specifically bind to phosphatidylcholine, phosphatidylcholine plasmalogen and sphingomyelin ${ }^{[20]}$. Other studies reported that these proteins bound to high-density lipoprotein, heparin and a glycosaminoglycan ${ }^{[21]}$. The BSP proteins and heparin stimulated cholesterol and phospholipid efflux from the sperm membrane and lipid efflux from sperm was found to be dependent on the BSP protein concentration $^{[22]}$. The loss of membrane cholesterol is an important step in sperm capacitation ${ }^{[23]}$. These studies clearly indicate that BSP proteins play a role in sperm capacitation. Recently, BSP family proteins were reported to occur ubiquitously in goat seminal plasma (GSP-14, GSP-15, GSP-20 and GSP-22 kDa) ${ }^{[24]}$. Homologous proteins have been purified from stallion seminal plasma (HSP-1 and 2) ${ }^{[25]}$ and boar seminal plasma (posttranslational modifications of boar glycoprotein $\mathrm{pB} 1)^{[26]}$. They have also been detected in low concentrations in other mammalian seminal plasma. Boisvert et al. ${ }^{[27]}$ also isolated and characterized homologous proteins from bison seminal vesicle secretion (BiSV-16, BiSV-17, BiSV-18 and BiSV-28 kDa). Furthermore, De Souza et al. ${ }^{[28]}$ identified these heparin-binding proteins, particularly the $61.5 \mathrm{kDa}$ protein, in the prostate secretions of 3 crossbred dogs and investigated whether these proteins were involved in the acrosome reaction of sperm. Cross $^{[2]}$ reported that prostasomes that are expelled from the prostate gland at ejaculation contain large amounts of cholestero and the fusion between prostasomes and sperm enriches the sperm membrane in cholesterol, thereby delaying the acrosome reaction and decreasing membrane fluidity ${ }^{[1,3,29]}$.

Thus, these contradictory results indicate that the first and third secretions from the prostate gland of the dog might result in a complex mixture containing a wide variety of components that affect the physiological functions of sperm. In other words, the freezability and fertility of sperm are dramatically altered by contact with fluids from these glands at ejaculation in vitro. Yamashiro et al. ${ }^{[30]}$ examined the significance of reducing the contact between seminal plasma and goat sperm at ejaculation. They suggested that the in vitro functional characteristics of the sperm were abruptly modified by flash sperm contact with accessory sex gland fluid at ejaculation. Further, comprehensive analysis of the protein constituents of the first and third prostatic fluid fractions from dog has not been reported. This study was designed to: (1) Investigate the spermatozoal effects of prostatic fluid from the first and third fractions following cryopreservation in two poodle dogs; and (2) Compare the protein composition of both prostatic fluids using sodium dodecyl sulfate-polyacrylamide gel electrophoresis (SDS-PAGE).

\section{MATERIALS AND MATHODS}

Sperm and prostatic fluid collection: The semen from 2 trained poodle dogs (Dog A: 7 years old, Dog B: 4 years old) was collected by digital stimulation in the absence of a tester female at almost weekly intervals. Total 9 collections from each dog were used for analyses in this experiment. The collection protocols consisted of : (1) Only sperm-rich fraction (first and third fraction were also collected separately for protein analysis); (2) sperm-rich fraction collected together with the first fraction and (3) Sperm-rich fraction collected together with the third fraction, or 3 replicated each treatment, respectively. Both prostatic fluid fractions that were collected separately for protein analysis was stored $-80^{\circ} \mathrm{C}$ until further analysis of prostatic fluid proteins.

Freezing extender: The basic semen extender was modified as described by Yamashiro et al. ${ }^{[31]}$ and consisted of a Tris(hydroxymethyl-aminomethane)Citric acid-Glucose (TCG) solution containing $375 \mathrm{mM}$ Tris (Sigma, St. Louis, MO, USA), $124 \mathrm{mM}$ citric acid (Wako Pure Chemical Industries, Ltd., Osaka, Japan) and $41 \mathrm{mM}$ glucose (Wako). This solution was adjusted 
to $\mathrm{pH} 7.3$ (with $375 \mathrm{mM}$ Tris) and an osmolarity of 350 mOsm.

Raffinose (Sigma) was added at a concentration of $0.05 \mathrm{M}$ in the TCG solution (385 mOsm at $\mathrm{pH} 7.3$ ) by a procedure that was modified from Yamashiro et al.$^{[32]}$. The osmotic pressure of this extender was $385 \mathrm{mOsm}$ at $\mathrm{pH}$ 7.3. Sodium dodecyl sulfate (0.04\%; SDS, Sigma) (w/v) was then added to the solution, followed by $20 \%$ (v/v) egg yolk and the extender was stirred for $30 \mathrm{~min}$. The solutions were then centrifuged twice at $6000 \mathrm{rpm}$ for $30 \mathrm{~min}$. The supernatants were filtered through a $0.45-\mu \mathrm{m}$ membrane filter (Sartorius, Germany). Finally, Bovine Serum Albumin (BSA) (1\% w/v) (Sigma) was added, thereby completing the raffinose-TCG egg yolk extender solution.

Semen evaluation: Immediately after each time a collection, the volume and sperm concentration of the sperm-rich fraction (Dog A: $0.6 \mathrm{~mL}, 66.8 \times 10^{6}$ sperm $\mathrm{mL}^{-1}$; Dog B: $0.15 \mathrm{~mL}, 66.2 \times 10^{6}$ sperm $\mathrm{mL}^{-1}$ ), spermrich fraction collected together with the first fraction (Dog A: $1.1 \mathrm{~mL}, 45.6 \times 10^{6}$ sperm $\mathrm{mL}^{-1}$; Dog B: $0.2 \mathrm{~mL}$, $58.4 \times 10^{6}$ sperm $\mathrm{mL}^{-1}$ ), or sperm-rich fraction collected together with the third fraction (Dog A: $1.5 \mathrm{~mL}$, $27.5 \times 10^{6} \quad$ sperm $\mathrm{mL}^{-1}$; $\operatorname{Dog}$ B: $0.9 \mathrm{~mL}$, $41.0 \times 10^{6}$ sperm $\mathrm{mL}^{-1}$ ) was measured. The percentages of motile sperm and forward progressive motility were evaluated subjectively by one observer. The Sperm Motility Index $(\mathrm{SMI}=\%$ motile $\operatorname{sperm}+(\%$ forward progressive motility $\times 20) / 2$ ) was calculated according to the method described by Comizzoli et al. ${ }^{[33]}$.

After collection, aliquots of sperm were assessed for viability by using SYBR-14 and propidium iodide (PI) (LIVE/DEAD Sperm Viability Kit, Molecular Probes, Eugene, Oregon), as described by ${ }^{[34]}$. Briefly, semen was diluted in HEPES-buffered saline containing $0.1 \%$ BSA (HEPES-0.1\% BSA). The HEPES-0.1\% BSA solution, which contained $0.760 \mathrm{~g} \mathrm{NaCl}$ (Wako), $0.030 \mathrm{~g} \mathrm{KCl}$ (Wako), $0.252 \mathrm{~g}$ fructose (Wako), $0.238 \mathrm{~g}$ HEPES (Wako), 0.015 g CaC12 (Wako), $0.010 \mathrm{~g}$ $\mathrm{MgC} 12$ (Wako) and $0.10 \mathrm{~g} \mathrm{BSA} 100 \mathrm{~mL}^{-1}$, was titrated to $\mathrm{pH} 7.3$ with $\mathrm{NaOH}$ before use and the concentration of the semen samples was adjusted to approximately $20 \times 10^{6}$ sperm $\mathrm{mL}^{-1}$. Three microliters of SYBR-14 was added to $1 \mathrm{~mL}$ of diluted semen, resulting in a final SYBR-14 concentration of $100 \mathrm{nM}$. PI was added to the $1 \mathrm{~mL}$ samples of diluted semen, resulting in a final PI concentration of $12 \mu \mathrm{M}$. The sample was incubated for $10 \mathrm{~min}$ at $37^{\circ} \mathrm{C}$. SYBR-14 stains only living sperm and results in bright green fluorescence of the acrosome upon excitation at $488 \mathrm{~nm}$. This stain was used to estimate the proportion of living sperm in dog sperm. It was used in combination with PI, which is used to assess dead sperm and stains bright red. Aliquots $(10 \mu \mathrm{L})$ of semen samples were smeared onto a microscopic slide. The proportion of SYBR-14 and PIstained sperm in each sample was then counted in more than 200 sperm and the result was expressed as the percentage of viability.

The acrosome status of fresh and frozen-thawed sperm was assessed by staining with FITC-PNA (Sigma) using a modification of the method described by $^{[30]}$. The percentage of intact acrosome was calculated after collection and freeze-thaw of 200 sperm that were randomly selected on each slide. The acrosome was considered to be intact when the stain was clearly and evenly distributed over the sperm, anterior to the equatorial segment.

The frozen-thawed sperm motility and velocity characteristics were assessed using a sperm motility analysis system (SMAS, Version 1.0; Kashimura, Tokyo, Japan); this was modified as described by Komori et al. ${ }^{[35]}$. At least 100 sperm and three fields were assessed by SMAS for each treatment group. Parameters assessed in this study were: motility (\%), straight line velocity (VSL; $\mu \mathrm{m} \mathrm{sec}{ }^{-1}$ ), curvilinear velocity (VCL; $\mu \mathrm{m} \mathrm{sec}{ }^{-1}$ ), amplitude of lateral head displacement (ALH; $\mu \mathrm{m})$ and beat cross frequency (BCF; Hz). The SMAS motility parameters used were those recommended by the manufacturer for sperm.

Freezing and thawing procedure: The freezing protocol was performed by two-step dilution according to the method described by Yamashiro et al. ${ }^{[36]}$. Immediately after collection, the semen was diluted 1:2 with the raffinose TCG-egg yolk extender solution at $30^{\circ} \mathrm{C}$. The tubes containing ejaculates were kept at $30^{\circ} \mathrm{C}$ and transferred to the laboratory within $30 \mathrm{~min}$ (time elapsed before cooling). Semen samples were cooled to $5^{\circ} \mathrm{C}$ for $90 \mathrm{~min}$. These were then further diluted with an equal volume of raffinose with TCGegg yolk extender containing $8 \%$ glycerol (Wako). The diluted semen was then equilibrated at $5^{\circ} \mathrm{C}$ for $90 \mathrm{~min}$ before freezing. Aliquots of $0.5 \mathrm{~mL}$ of sperm suspension were placed in straws and the ends were then sealed. The straws were then placed in liquid nitrogen vapor for $10 \mathrm{~min}$ then directly plunged into liquid nitrogen. Frozen sperm were thawed by holding the straws for $10 \mathrm{~s}$ in a water bath at $37^{\circ} \mathrm{C}$. They were then diluted 1:1 with the TCG solution and allowed to equilibrate in an incubator at $37^{\circ} \mathrm{C}$ for $5 \mathrm{~min}$ prior to post-thaw analysis. Post-thaw motility parameters were 
evaluated by using SMAS and the acrosome integrity of frozen-thawed sperm was also assessed.

SDS-PAGE: SDS-PAGE was performed in 15\% polyacrylamide gels according to the method of Yokoo et al. ${ }^{[37]}$ using a gel electrophoresis apparatus (Atto, Tokyo, Japan). The three prostatic fluids from the first and third fractions of the ejaculates-samples were centrifuged twice at $12000 \mathrm{rpm}$ for $5 \mathrm{~min}$ to remove the sperm before analysis. Protein concentrations were measured at OD $280 \mathrm{~nm}$ using Nanodrop ND-1000 (Nanodrop Technologies, Wilmington, DE). Samples containing $30 \mu \mathrm{g}$ of proteins were diluted $1: 1(\mathrm{v} / \mathrm{v})$ with the sample buffer ( $40 \mathrm{~mL}$ glycerol, $4.3 \mathrm{~g}$ SDS, $10 \mathrm{~mL} 2-$ mercaptoethanol (Wako) and Tris- $\mathrm{HCl}(\mathrm{pH} \mathrm{6.8)}$ ) and made up to a volume of $100 \mathrm{~mL}$ using D-H2O). These were then heated for $5 \mathrm{~min}$ at $95^{\circ} \mathrm{C}$. Electrophoresis was performed for $2 \mathrm{~h}$ at $18 \mathrm{~mA}$. Gels were stained with $0.025 \%$ Coomassie Brilliant Blue R250 (Fluka, Gillingham, Dorset, UK).

Statistical analysis: The data were analyzed by repeated-measures ANOVA using the Statview program (Abacus Concepts, Berkeley, CA). Differences between individual groups were examined with the Fisher Probable Least-Square Difference (PLSD) test and three separate ejaculates were repeated 3 times on independent samples. All data are expressed as mean \pm SEM. Probability values of $\mathrm{p}<0.05$ were considered to be significant.

\section{RESULTS}

Experiment 1: Effect of prostatic fluid from the first and third fractions on the cryosurvival of dog sperm: The effects of prostatic fluid from the first and third fractions of canine ejaculates on sperm characteristics are shown in Table 1. When second and third fractions were combined, the viability of Dog A sperm decreased significantly $(p<0.05)$ when compared to second fraction alone or when second fraction was combined with prostatic fluid from the first fraction (Table 1). However, in the case of Dog B. sperm that had been collected in the presence of prostatic fluids at ejaculation, there was no significant difference in the SMI, viability and proportion of acrosome intact sperm.

The post-thaw sperm motility of the sperm-rich fraction from Dog A that did not contain any prostatic fluid fraction was significantly higher $(\mathrm{p}<0.05)$ than that of the sperm that were frozen with the first or third prostatic fluid fraction. No other differences were found with addition of prostatic fluid. When the sperm from Dog B were frozen, motility did not differ among the tested treatments. However, the post thaw VSL, VCL and ALD of sperm from Dog B that were collected with prostatic fluid tended to be higher than those of sperm collected with the first or third fraction of ejaculates. The proportion of Dog B sperm with an intact acrosome did not differ between the collection and freeze-thaw methods.

Experiment 2: SDS-PAGE patterns in prostatic fluid from the first and third fractions: SDS-PAGE analyses were performed to verify whether any modifications appeared in the protein patterns of the first and third fractions (Fig. 1). The total amounts of proteins present in the third prostatic fluid were $11.0 \pm 1.9$ and $10.4 \pm 2.4 \mu \mathrm{g} \mathrm{mL}^{-1}$ in Dogs A and B, respectively. In the first prostatic fluid, these values were $22.4 \pm 7.2$ and $30.6 \pm 9.7 \mu \mathrm{g} \mathrm{mL} \mathrm{m}^{-1}$, respectively. Electrophoresis analysis results indicated the presence of 2 main bands in both the prostatic fluid from the first and third fractions of the ejaculates. These bands corresponded to proteins of molecular mass 30 and $75 \mathrm{kDa}$. However, the amount of $30 \mathrm{kDa}$ protein was appeared higher in the third fraction of prostatic fluid than in the first fraction.

Table 1: Effect of prostatic fluid on pre-freezing and post-thawing sperm characteristics

\begin{tabular}{|c|c|c|c|c|c|c|c|c|c|c|}
\hline \multirow[b]{3}{*}{ Dog } & \multirow[b]{3}{*}{$\begin{array}{l}\text { Treatment } \\
\text { (Fraction) }\end{array}$} & \multicolumn{8}{|c|}{ Sperm characteristics } & \\
\hline & & \multicolumn{4}{|c|}{ After collection } & \multicolumn{5}{|c|}{ Post-thawing } \\
\hline & & $\begin{array}{l}\text { Sperm } \\
\text { motility } \\
\text { index }(\%)^{1}\end{array}$ & $\begin{array}{l}\text { Viability } \\
(\%)\end{array}$ & $\begin{array}{l}\text { Acrosome } \\
\text { integrity } \\
(\%)\end{array}$ & $\begin{array}{l}\text { Motility } \\
(\%)\end{array}$ & $\begin{array}{l}\text { Straight } \\
\text { line } \\
\text { velocity } \\
\left.(\mu \mathrm{m} \mathrm{sec})^{-1}\right)\end{array}$ & $\begin{array}{l}\text { Curvilinear } \\
\text { velocity } \\
\left(\mu \mathrm{mec}^{-1}\right)\end{array}$ & $\begin{array}{l}\text { Amplitude of } \\
\text { lateral head } \\
\text { displacement } \\
(\mu \mathrm{m})\end{array}$ & $\begin{array}{l}\text { Beat cross } \\
\text { frequency } \\
(\mathrm{Hz})\end{array}$ & $\begin{array}{l}\text { Acrosome } \\
\text { Integrity } \\
(\%)\end{array}$ \\
\hline \multirow[t]{3}{*}{$\operatorname{Dog} \mathrm{A}$} & Sperm-rich & $82.5 \pm 3.8$ & $89.1 \pm 2.1^{\mathrm{a}}$ & $86.3 \pm 3.6$ & $70.1 \pm 3.4^{\mathrm{a}}$ & $19.9 \pm 1.1$ & $71.1 \pm 5.9$ & $1.9 \pm 0.08^{\mathrm{ab}}$ & $16.6 \pm 0.4$ & $70.3 \pm 3.0$ \\
\hline & First+Sperm-rich & $64.5 \pm 13.1$ & $83.9 \pm 0.6^{\mathrm{a}}$ & $78.1 \pm 2.8$ & $58.0 \pm 4.2^{\mathrm{a}}$ & $20.5 \pm 1.2$ & $70.5 \pm 1.4$ & $1.8 \pm 0.05^{\mathrm{a}}$ & $16.2 \pm 0.3$ & $73.4 \pm 3.1$ \\
\hline & Sperm-rich+Third & $64.5 \pm 7.3$ & $79.5 \pm 1.7^{\mathrm{b}}$ & $81.1 \pm 3.0$ & $39.8 \pm 8.2^{\mathrm{b}}$ & $18.3 \pm 3.5$ & $76.8 \pm 3.4$ & $2.1 \pm 0.1^{\mathrm{b}}$ & $19.2 \pm 1.9$ & $69.9 \pm 2.5$ \\
\hline \multirow[t]{3}{*}{ Dog B } & Sperm-rich & $67.9 \pm 14.7$ & $78.8 \pm 1.8$ & $78.3 \pm 3.8$ & $53.5 \pm 13.7$ & $22.6 \pm 5.8$ & $90.5 \pm 10.8$ & $2.5 \pm 0.02^{\mathrm{a}}$ & $18.4 \pm 1.2$ & $71.9 \pm 3.2$ \\
\hline & First+ Sperm-rich & $58.7 \pm 8.7$ & $75.1 \pm 3.5$ & $73.6 \pm 2.7$ & $60.7 \pm 6.3$ & $15.5 \pm 2.0$ & $72.7 \pm 3.7$ & $2.1 \pm 0.1^{\mathrm{a}}$ & $20.2 \pm 1.3$ & $71.6 \pm 3.2$ \\
\hline & Sperm-rich+Third & $69.1 \pm 6.8$ & $75.5 \pm 0.8$ & $73.5 \pm 2.9$ & $50.8 \pm 7.5$ & $17.6 \pm 1.0$ & $70.4 \pm 1.2$ & $1.8 \pm 0.03^{\mathrm{b}}$ & $17.4 \pm 0.3$ & $67.9 \pm 2.6$ \\
\hline
\end{tabular}




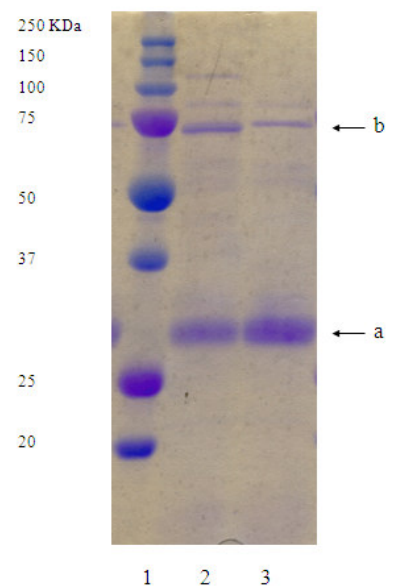

(a)

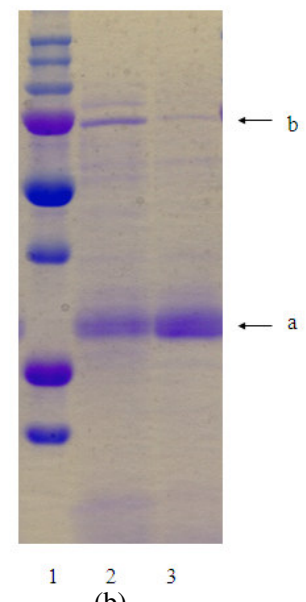

(b)
Fig. 1: Coomassie blue-stained proteins bands from the first and third prostatic fluid fractions of a poodle dog separated by SDS-PAGE. (a): Dog A prostatic fluid and (b): Dog B prostatic fluid. Each lane of the $15 \%$ polyacrylamide gel was loaded with $30 \mu \mathrm{g}$ of protein. (Lane 1): Molecular weight markers; (Lane 2): First fraction of poodle dog prostatic fluid proteins (Lane 3): Third fraction of poodle dog prostatic fluid proteins. The letters $\mathrm{a}$ and $\mathrm{b}$ indicate poodle dog prostatic fluid proteins of molecular masses 30 and $75 \mathrm{kDa}$, respectively

\section{DISCUSSION}

The physiologic function of mammalian seminal plasma has been investigated in vivo and in vitro by several researchers. In vitro functional characteristics of goat sperm are abruptly modified by flash contact with accessory gland fluid at ejaculation ${ }^{[30]}$. Prostasomes are membranous vesicles secreted by the prostate gland that are surrounded by a bilaminar or multilaminar lipoprotein and contain large amounts of cholesterol, sphingomyelin, calcium and different enzymes ${ }^{[3]}$. The fusion of prostatomes to sperm enriches the sperm membrane with cholesterol and sphingomyelin and results in bursts of intracytoplasmic sperm calcium at the moment of ejaculation ${ }^{[1]}$. Carlini and colleagues ${ }^{[29]}$ measured the fluidity of the sperm membrane pre-and post-prostatome fusion and reported that enrichment of cholesterol in the sperm membrane reduces membrane fluidity, thereby delaying the acrosome reaction.

Dog ejaculates consist of 3 fractions. The first and third fractions originate predominately from the prostate gland and contain few to no sperm $^{[9,10,38]}$. Yu and Coworkers ${ }^{[38]}$ reported significant differences in the physiologic characteristics of epididymal and ejaculated sperm, especially in terms of sensitivity to cold. The current study investigated the effect of prostatic fluid on poodle dog sperm following cryopreservation. In Dog A, the post-thaw sperm motility was significantly reduced when prostatic fluid was added. Conversely, the percentage of motile sperm after freezing and thawing was not noticeably affected with the addition of prostatic fluid in Dog B. However, VSL, VCL and ADL characteristics tended to be higher in the absence of prostatic fluid. These results indicate that the in vitro effects of prostatic fluid from the first and third fractions of the ejaculates vary depending upon individual dog.

Manjunath and Sairam ${ }^{[4]}$ reported the detrimental effects of seminal plasma on bovine sperm membrane integrity in vitro and identified four inhibitory protein factors secreted from the seminal vesicles in bulls (Bovine Seminal Plasma (BSP)-A1, BSP-A2, BSP-A3 and $\mathrm{BSP}-30 \mathrm{kDa}$ ). These proteins also bind to the sperm surface at ejaculation via interactions with choline phospholipids present in the sperm membrane. These proteins appear to participate in the bovine sperm membrane lipid modifications that occur during Capacitation $^{[39]}$. De Souza and coworkers ${ }^{[28]}$ reported that the proteins resembling BSP were found in crossbred dog seminal plasma (58.6, 67 and $61.5 \mathrm{kDa})$. However, these investigators did not show whether these proteins were present in all fractions of the ejaculates or if they were only found in prostatic fluid. Using SDS-PAGE analysis, the current study demonstrated that the major proteins in poodle dog prostatic fluid were 30 and $75 \mathrm{kDa}$ and that there was twice-three times as much protein present in the third fraction compared to the first fraction. In the present study, the motility parameters of the sperm-rich fraction were enhanced when it was collected and frozen in the absence of prostatic fluid. This may be due to the lack of inhibiting factors within the prostatic fluid, such as prostatomes or the $30 \mathrm{kDa}$ protein identified in the current study, which in turn promotes sperm functions including motility and cryosurvivability. These proteins may play a significant role in a great variety of physical processes that regulate sperm membrane function post ejaculation and cryopreservation.

\section{CONCLUSION}

Prostatic fluid from both the first and third fraction of the canine ejaculates contains $30 \mathrm{kDa}$ and $75 \mathrm{kDa}$ molecular weight proteins. The total amount of protein present in prostatic fluid from the third fraction is two to three fold higher than in the first fraction. The addition of prostatic fluid to the sperm-rich fraction decreases motility and diminishes viability of frozenthawed poodle dog sperm. Future studies analyzing the 
biochemical functions of prostatic fluid serve as to develop a marker for predicting the freezability and fertility of dog sperm.

\section{ACKNOWLEDGMENT}

This study was partly supported by a grant from the Japan Animal Specialty College (to Eimei Sato). We also thank Dr. Hiroyuki Abe, Yamagata University, for his technical advice on sperm motility analysis.

\section{REFERENCES}

1. Arienti, G., E. Carlin, C. Saccardi and C.A. Palmerini, 2004. Role of human prostasomes in the activation of spermatozoa. J. Cell. Mol. Med., 8: 77-84. DOI: 10.1111/j.1582-4934.2004.tb00261.x

2. Cross, N.L. and P. Mahasreshti, 1997. Prostasome fraction of human seminal plasma prevents sperm from becoming acrosomally responsive to the agonist progesterone. Arch. Androl., 39: 39-44. DOI: 10.3109/01485019708987900

3. Kravets, F.G., L. Lee, B. Singh, A. Trocchia, S.N. Pentyala and S.A. Khan, 2000. Prostasomes: Current concepts. Prostate, 43: 169-174. http://www.ncbi.nlm.nih.gov/pubmed/10797491

4. Manjunath, P. and M.R. Sairam, 1987. Purification and biochemical characterization of three major acidic proteins (BSP-A1, BSP-A2 and BSP-A3) from bovine seminal plasma. Biochem. J., 241: 685-692. http://www.pubmedcentral.nih.gov/articlerender.fc gi?tool=pubmed $\&$ pubmedid $=3593217$

5. Moreau, R. and P. Manjunath, 2000. Characteristics of the cholesterol efflux induced by novel seminal phospholipid-binding proteins. Biochim. Biophys. Acta, 1487: 24-32. DOI: 10.1016/S1388-1981(00)00080-9

6. Dott, H.M., 1974. The effects of bovine seminal plasma on the impedance change frequency and glycolysis of bovine epididymal spermatozoa. J. Reprod. $\quad$ Fertil., $\quad 38$ : 147-156. http://www.ncbi.nlm.nih.gov/pubmed/4841387

7. Pesch, S., M. Bergmann and H. Bostedt, 2006. Determination of some enzymes and macro-and microelements in stallion seminal plasma and their correlations to semen quality. Theriogenology, 66: 307-313.

DOI: $10.1016 /$ j.theriogenology.2005.11.015

8. Shannon, P., 1965. Presence of a heat-labile toxic protein in bovine seminal plasma. J. Dairy Sci., 48: 1362-1365. http://www.ncbi.nlm.nih.gov/pubmed/5893406

9. England, G.C.W., W.A. Allen and D.J. Middleton, 1990. An investigation into the origin of the first fraction of the canine ejaculate. Res. Vet. Sci., 49: 66-70.

http://www.ncbi.nlm.nih.gov/pubmed/2382057
10. Rota, A., C. Milani and S. Romagnoli, 2007. Effect of post-thaw dilution with autologous prostatic fluid on dog semen motility and sperm acrosome status. Theriogenology, 67: 520-525. DOI: 10.1016/j.theriogenology.2006.09.001

11. Rota, A., B. Strom and C. Linde-Forsberg, 1995. Effects of seminal plasma and three extenders on canine semen stored at $4^{\circ} \mathrm{C}$. Theriogenology, 44: 885-900. DOI: 10.1016/0093-691X(95)00278-G

12. Sirivaidyapong, S., P. Ursem, M.M. Bevers and B. Colenbrander, 2001. Effect of prostatic fluid on motility, viability and acrosome integrity of chilled and frozen-thawed dog spermatozoa. J. Reprod. Fertil. Suppl., 57: 383-386. http://www.ncbi.nlm.nih.gov/pubmed/11787180

13. Dott, H.M., R.A.P. Harrison and C.A. Foster, 1979. The maintenance of motility and the surface properties of epididymal spermatozoa from bull, rabbit and ram in homologous seminal and epididymal plasma. J. Reprod. Fertil., 55: 113-124. DOI: 10.1530/jrf.0.0550113

14. Hori, T., K. Hagiuda, E. Kawakami and T. Tsutsui, 2005. Unilateral intrauterine insemination with prostatic fluid-sensitized frozen caudal epididymal sperm in beagle dogs. Theriogenology, 63: 1573-1583. DOI: 10.1016/j.theriogenology.2004.05.027

15. Alghamdi, A.S., M.T. Troedsson, J.L. Xue and B.G. Crabo, 2002. Effect of seminal plasma concentration and various extenders on posthaw motility and glass wool-Sephadex filtration of cryopreserved stallion semen. Am. J. Vet. Res., 63: 880-885. http://cat.inist.fr/?aModele $=$ afficheN\&cpsidt $=13715148$

16. Berger, T. and E. Clegg, 1985. Effect of male accessory gland secretions on sensitivity of porcine sperm acrosomes to cold shock. Initiation of motility and loss of cytoplasmic droplets. J. Anim. Sci., 60: 1295-1302. http://jas.fass.org/cgi/content/abstract/60/5/1295

17. Graham, J.K, 1994. Effect of seminal plasma on the motility of the epididymal and ejaculated spermatozoa of the ram and bull during the cryopreservation process. Theriogenology, 41: 1151-1162. DOI: 10.1016/S0093-691X(05)80037-8

18. Perez-Pe, R., J.A. Cebrian-Perez and T. Muino-Blanco, 2001. Seminal plasma proteins prevent cold-shock membrane damage to ram spermatozoa. Theriogenology, 56: 425-434. DOI: 10.1016/S0093-691X(01)00574-X

19. Ben, W.X., M.T. Fu, L.K. Mao, Z.W. Ming and W.W. Xion, 1997. Effects of various concentrations of native seminal plasma in cryoprotectant on viability of human sperm. Arch. Androl., 39: 211-216. DOI: $10.3109 / 01485019708987918$ 
20. Desnoyers, L. and P. Manjunath, 1992. Major proteins of bovine seminal plasma exhibit novel interactions with phospholipids. J. Biol. Chem., 267: 10149-10155. http://www.ncbi.nlm.nih.gov/pubmed/1577785

21. Manjunath, P., Y.L. Marcel, J. Uma, N.G. Seidah, M. Chretien and A. Chapdelaine, 1989. Apoliproprotein A-I binds to a family of bovine seminal plasma proteins. J. Biol. Chem., 264: 16853-16857. http://www.ncbi.nlm.nih.gov/pubmed/2506184

22. Manjunath, P. and I. Therien, 2002. Role of seminal plasma phospholipids-binding proteins in sperm membrane lipid modification that occurs during capacitation. J. Reprod. Immunol., 53: 109-119. DOI: 10.1016/S0165-0378(01)00098-5

23. Yanagimachi, R., 1969. In vitro capacitation of hamster spermatozoa by follicular fluid. J. Reprod. Fertil., $\quad$ 18: 275-286. http://www.ncbi.nlm.nih.gov/pubmed/5815307

24. Villemure, M., C. Lazure and P. Manjunath, 2003. Isolation and characterization of gelatin-binding proteins from goat seminal plasma. Reprod. Biol. Endocrinol., 1: 39. DOI: 10.1186/1477-7827-1-39

25. Menars, M., V. Nauc, C. Lazure, D. Vaillancourt and P. Manjunath, 2003. Novel purification method for mammalian seminal plasma phospholipidsbinding proteins reveals the presence of a novel member of this family of protein in stallion seminal fluid. Mol. Reprod. Develop., 66: 349-357. DOI: 10.1002/mrd.10369

26. Calvete, J.J., M. Raida, M. Gentzel, C. Urbanke, L. Sanz and L. Topfer-Peterson, 1997. Isolation and characterization of heparin-and phosphorylcholinebinding proteins of boar and stallion seminal plasma. Primary structure of porcine $\mathrm{pB} 1$. FEBS Lett., 407: 201-206. DOI: 10.1016/S00145793(97)00344-X

27. Boisvert, M., A. Bergeron, C. Lazure and P. Manjunath, 2004. Isolation and characterization of gelatinbinding bison seminal vesicle secretory proteins. Biol. Reprod., 70: 656-661. DOI: 10.1095/biolreprod.103.023069

28. De Souza, F.F., M.I.M. Martins, C.E.S. Fernandes, P.E.M. Ribolla and M.D. Lopes, 2006. Heparinbinding proteins of canine seminal plasma. Theriogenology, 66: 1606-1609. DOI: 10.1016/j.theriogenology.2006.02.016

29. Carlini, E., C.A. Palmerini, E.V. Cosmi and G. Arienti, 1997. Fusion of sperm with prostasomes: effects on membrane fluidity. Arch. Biochem. Biophys., 343: 6-12. DOI: 10.1006/abbi.1997.9999

30. Yamashiro, H., K. Kumamoto, H.F. Wang, Y. Yamashita and T. Terada, 2006. Effect of semen collection in extender solution on the characteristics of goat spermatozoa. J. Reprod. Develop., 52: 397-406. DOI: $10.1262 /$ jrd.17104
31. Yamashiro, H., H.F. Wang, Y. Yamashita, K. Kumamoto and T. Terada, 2006. Enhanced freezability of goat spermatozoa collected into tubes containing extender supplemented with Bovine Serum Albumin (BSA). J. Reprod. Develop., 52: 407-414. DOI: 10.1262/jrd.17105

32. Yamashiro, H., Y.J. Han, A. Sugawara, I. Tomioka, Y. Hoshino and E. Sato, 2007. Freezability of rat epididymal sperm induced by raffinose in modified Krebs-Ringer Bicarbonate (mKRB) based extender solution. Cryobiology, 55: 285-294. DOI: 10.1016/j.cryobiol.2007.08.011

33. Comizzoli, P., R. Mauget and P. Mermillod, 2001. Assessment of in vitro fertility of deer spermatozoa by heterologous IVF with zona-free bovine oocytes. Theriogenology, 56: 261-274. DOI: 10.1016/S0093-691X(01)00561-1

34. Garner, D.L., L.A. Johnson, S.T. Yue, B.L. Roth and R.P. Haugland, 1994. Dual DNA staining assessment of bovine sperm viability using SYBR14 and propidium iodide. J. Androl., 15: 620-629. http://www.ncbi.nlm.nih.gov/pubmed/7721666

35. Komori, K., A. Tsujimura, A. Ishijima, P. Tanjapatkul, K. Fujita, Y. Matsuoka, K. Takao, Y. Miyagawa, S. Takada and A. Okuyama, 2006. Comparative study of sperm motility analysis system and conventional microscopic semen analysis. Reprod. Med. Biol., 5: 195-200. DOI: 10.1111/j.14470578.2006.00141.x

36. Yamashiro, H., K. Narita, S. Sugimura, Y.J. Han, A. Sugawara, K. Morohaku, F. Nakazato, T. Konno, M. Yoshida and E. Sato, 2007. Trehalose enhanced the freezability of Poodle dog sperm collected by an Artificial Vagina (AV). Anim. Reprod. Sci., 102: $165-171$.

DOI: 10.1016/j.anireprosci.2007.02.026

37. Yokoo, M., Y. Miyahayashi, T. Nakamura, N. Kimura, H. Sasada and E. Sato, 2002. Identification of hyaluronic acid-binding proteins and their expressions in porcine cumulus-oocyte complexes during in vitro maturation. Biol. Reprod., 67: 1165-1171. DOI: 10.1095/biolreprod.102.004903

38. Yu, I., N. Songsasen, R.A. Godke and S.P. Leibo, 2002. Differences among dogs in response of their spermatozoa to cryopreservation using various cooling and warming rates. Cryobiology, 44: 62-78. http://www.ncbi.nlm.nih.gov/pubmed/12061849

39. Therien, I., R. Moreau and P. Manjunath, 1999. Bovine seminal plasma phospholipid-binding proteins stimulate phospholipids efflux from epididymal sperm. Biol. Reprod., 61: 590-598. http://www.biolreprod.org/cgi/content/full/61/3/590 